\title{
A REINVENÇÃO DO CONSERVADORISMO: OS EVANGÉLICOS E AS ELEIÇÕES FEDERAIS DE 2014
}

\author{
Marcelo Tadvald ${ }^{1}$ \\ Eis que Deus não rejeita ao integro, \\ nem toma pela mão os malfeitores. \\ (Jó 8:20)
}

Resumo: Analiso neste trabalho a atuação da Frente Parlamentar Evangélica, conhecida popularmente como bancada evangélica, a partir do resgate de alguns dados históricos e da atuação desta bancada na legislatura passada para avaliar a campanha eleitoral de 2014 e a sua composição atual, tendo em vista resgatar alguns de seus paradigmas e projetar a sua atuação na próxima legislatura do Parlamento brasileiro.

Palavras-chave: Religião; Política; Frente Parlamentar Evangélica; Eleições Federais de 2014.

Abstract: The purpose of this paper is to analyze the performance of the Evangelical Parliamentary Front, known popularly as evangelical stand, from the rescue of some historical data and the performance of this "stand" in the last legislature to evaluate the election campaign of 2014 and its composition current in order to rescue their paradigms to design your performance in the next legislature in the Brazilian Parliament.

Keywords: Religion; Politics; Evangelical Parliamentary Front; Federal Election 2014.

\footnotetext{
1 Doutor em Antropologia Social. Pesquisador associado ao Núcleo de Estudos da Religião (NER) e Pós-Doutorando (PNPD-Capes) do PPGAS-UFRGS, Brasil. Contato: marcelotadvald@hotmail.com
}

Debates do NER, Porto Alegre, ano I6, N. 27, P. 259-288, JAn./Jun. 2015 


\section{INTRODUÇÃO: OS EVANGÉLICOS E O LEGISLATIVO FEDERAL}

A partir da redemocratização, em 1985, a inserção evangélica na arena política revelou-se significativa, especialmente se levarmos em consideração o modelo evangélico de participação no campo político, sua instrumentalização e planejamento estratégico de conquista de votos e de poder.

Exceção feita aos pentecostais das Assembleias de Deus e aos Batistas, as denominações neopentecostais têm mostrado maior êxito em seus desafios eleitorais e de inserção na mídia, se comparados às demais denominações, em especial às do protestantismo histórico. A partir do modelo instaurado pela Igreja Universal do Reino de Deus (IURD) desde as eleições constituintes de 1986, as igrejas que obtêm maior sucesso nesta arena são aquelas que possuem projetos mais bem definidos de inserção na política e que utilizam seus templos e demais espaços religiosos, incluindo os virtuais, para fazer campanha para seus candidatos, dispondo de profusos meios materiais e midiáticos que contribuem na difusão das campanhas entre os seus fiéis e até para além deles (Freston, 1994).

Com o tempo, diante da defesa de temas políticos comuns, preferencialmente relacionados ao campo da moral e dos costumes, os deputados evangélicos formaram a Frente Parlamentar Evangélica (doravante FPE),

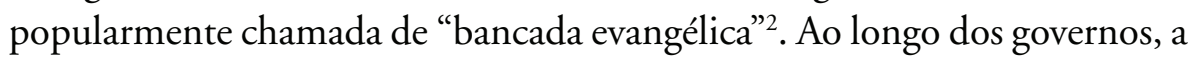
FPE é regularmente protagonista de diversas polêmicas, desde a sua postura conservadora diante de temas sociais de difícil trânsito e avanço junto a este que se trata, em última instância, de um país constitucionalmente laico. Temas como a legalização do aborto, descriminalização do uso de algumas substâncias psicoativas, os direitos sexuais e civis, a criminalização da homofobia, diminuição da maioridade penal, aplicação da Lei da Anistia, entre outros, revelaram que a FPE advoga se constituir numa espécie de "primado moral" da nação, contudo o histórico envolvimento de parlamentares da Frente em

2 A fim de saber mais sobre a organização, o funcionamento e cotidiano da FPE, ver o trabalho de Janine Trevisan (2013).

Debates do NER, Porto Alegre, ano i6, N. 27, P. 259-288, JAn./Jun. 2015 
diferentes casos de corrupção refutou a ideia desta suposta primazia moral pela qual se pretende vigilante e modelar. Algo que, todavia, não esvaziou o seu prestígio junto às suas populações eleitorais, que seguem votando nos candidatos oficiais lançados por suas igrejas.

Segundo Ricardo Mariano (2011), até o final dos anos 1970, a maioria das igrejas pentecostais opunha-se à participação política. Em geral, apoiadores do regime militar, imperava à época a bravata: "crente não se mete em política" ou, no máximo, "crente deve votar no governo". Tal quadro mudou, nos anos 1980, com a nova Constituição, transformando também a bravata político-evangélica para o corrente "irmão vota em irmão". No prelúdio da redemocratização, a Assembleia de Deus disseminou o boato de que a Igreja Católica pretendia tornar o catolicismo religião oficial do país, o que resultaria em perseguiçōes religiosas. Por isso, decidiu participar da escritura da nova Carta Magna, mobilizando o seu "rebanho eleitoral", o que deu resultado, já que, se em 1982 os pentecostais lograram eleger apenas dois deputados federais, em 1986, elegeram dezoito, o que significou o grande marco de ingresso evangélico na política. Desde então, a participação desses segmentos só cresceu.

Excetuando-se a campanha eleitoral de 2006 (legislatura 2007-2010), quando certas denominações, como a IURD, resolveram preservar alguns campeóes de voto envolvidos em escândalos de corrupção não os lançando candidatos, o que diminuiu sensivelmente a FPE daquela legislatura, nas demais, o que se tem observado é a manutenção de certo contingente de parlamentares evangélicos.

O progressivo fortalecimento das instituições democráticas no país desde o final da ditadura civil-militar, em 1985, e impulsionado pelo crescimento econômico verificado desde a primeira década do século XXI tem possibilitado que grupos sociais portadores de alteridades historicamente marginalizadas pelo discurso oficial reanimem suas demandas por políticas de reconhecimento de identidade e de integração na sociedade nacional. Como efeito desta maior visibilidade, nos últimos anos, a bancada evangélica tem assumido a tarefa de se estabelecer como o repositório

Debates do NER, Porto Alegre, ano I6, N. 27, P. 259-288, JAn./Jun. 2015 
e a voz na nação do conservadorismo dogmático cristão que dele é constituído e constituinte. Contudo, quando postas em questão pelo parlamento certas questôes polêmicas, como as já referidas, a esta Frente religiosa se soma o apoio de outros grupos de representação parlamentar também coalizantes de perspectivas conservadoras semelhantes, como é o caso de diversos integrantes da chamada bancada ruralista, apenas para nos determos na esfera das frentes parlamentares. Aliás, não é incomum que membros da FPE também sejam integrantes de outras bancadas, especialmente a ruralista.

Os evangélicos têm crescido no Brasil. Se, conforme o Censo de 1940, eles contabilizavam 2,6\% da população, no Censo de 2000, eles representavam 9\% até chegar aos dados atuais apurados pelo Censo de 2010, que dão conta de que atualmente $22,2 \%$ da população brasileira se assume evangélica, um acréscimo de 16 milhões de pessoas na última década (de 26,2 milhões para 42,3 milhões) (Tadvald, 2013). Assim, de acordo com certas previsões fortuitas que contam atualmente com cerca de vinte anos, se, no caso geral da América Latina, conforme sugeriu André Corten (1996), o pentecostalismo conseguiu modificar a base teológica-política desta região, no caso específico do Brasil, segundo sugeriu Paul Freston (1994), seja por aproximação, distanciamento, repúdio ou indiferença, não há mais como pensar a política do país sem levar em consideração o campo evangélico. $\mathrm{O}$ quadro a seguir indica, a partir dos números, tais prerrogativas.

Quadro 1 - Número de deputados federais e senadores evangélicos eleitos (1982-2014)

\begin{tabular}{|c|c|c|}
\hline Ano Eleitoral - Legislatura & Deputados Federais & Senadores \\
\hline$(1982) 1983-1987$ & 12 & - \\
\hline$(1986) 1987-1991$ & 33 & - \\
\hline$(1990) 1991-1995$ & 23 & 5 \\
\hline$(1994) 1995-1999$ & 32 & 1 \\
\hline
\end{tabular}

Debates do NER, Porto Alegre, Ano i6, N. 27, P. 259-288, JAn./Jun. 2015 


\begin{tabular}{|c|c|c|}
\hline (1998) 1999-2003 & 49 & 2 \\
\hline$(2002) 2003-2007$ & 59 & 4 \\
\hline$(2006) 2007-2011$ & 30 & 2 \\
\hline$(2010) 2011-2014$ & 63 & 3 \\
\hline$(2014) 2015-2018$ & 67 & 3 \\
\hline
\end{tabular}

Fontes: Fonseca, 1998; Freston, 2001. Disponível em: <http://www.camara.gov.br>.; <www.diap.org.br>. Acesso em: 7 jan. 2015.

Excetuando-se a legislatura que teve início em 2015, em trabalho anterior (Tadvald, 2010), ofereci um quadro com o histórico político dos evangélicos eleitos ao menos uma vez para o Senado ou para a Câmara dos Deputados nos pleitos a contar de 1998. Neste levantamento, que contou com 142 parlamentares, verifiquei algumas tendências no que diz respeito ao perfil dos políticos evangélicos. Por exemplo, apenas $11 \%$ do total eram mulheres; a maioria dos parlamentares é oriunda das Assembleias de Deus, da IURD e da Igreja Batista, mas também é digno de nota representantes presbiterianos, luteranos, do Evangelho Quadrangular, da Igreja Internacional da Graça de Deus, da Sara Nossa Terra, Igreja Maranata, entre outras denominações. Com relação aos Estados da Federação, os maiores colégios eleitorais do país são também responsáveis pela eleição da maioria dos parlamentares evangélicos, destacando-se então, nesta ordem, o Rio de Janeiro, seguido por São Paulo, Minas Gerais e Bahia. Com relação aos partidos políticos, os dados indicaram baixíssima fidelidade partidária mediante o expressivo trânsito dos candidatos entre diferentes legendas, notoriamente de ideologia considerada de "direita". Muito discutiu-se, ao longo das duas últimas décadas, a respeito da criação de um partido evangélico, mas o mais próximo disso observado consiste na estratégia adotada por algumas denominações, como a IURD, de lançar todos os seus candidatos pela mesma legenda. Por exemplo, se outrora isto aconteceu com o PL, atualmente a IURD investe no PRB para tal fim.

Debates do NER, Porto Alegre, ano I6, N. 27, P. 259-288, JAn./Jun. 2015 
Antes de apresentarmos os dados relativos ao pleito federal de 2014, é importante trazermos à luz as eleiçôes anteriores e, especialmente, a projeção nacional que recebeu a FPE na legislatura passada, em boa medida devido à atuação de parlamentares tais como a do assembleiano Marco Feliciano e sua atividade enquanto presidente da Comissão de Direitos Humanos e Minorias (CDHM) da Câmara dos Deputados do Brasil.

\section{A LEGISLATURA PASSADA (2011-2014)}

O pleito federal de 2010 foi estratégico para os evangélicos no sentido de retomar a força de sua representação em grande medida enfraquecida diante do resultado do pleito de 2006 que, conforme mencionado, diminuiu sensivelmente o número de cadeiras da bancada evangélica devido ao envolvimento de seus parlamentares em escândalos de corrupção (especialmente os casos do "Mensalão" e das "Sanguessugas") e ao cálculo, promovido por algumas denominações, de preservação de seus candidatos, não lançados às urnas (Tadvald, 2006).

No pleito de 2010, a bancada evangélica baseou a sua plataforma política na luta contra medidas constantes no Plano Nacional de Direitos Humanos (PNDH-3), lançado pelo governo Lula em 21 de dezembro de 2009, que, dentre outros aspectos, previa a descriminalização do aborto e a união civil de pessoas do mesmo sexo. A bancada também investiu contra a homoafetividade ao defender que era dever do Estado disponibilizar meios para os indivíduos resgatarem a sua condição original de gênero e combateu projetos que tornariam crime a discriminação por orientação sexual e identidade de gênero. Ademais, a FPE fez campanha a favor do Estatuto do Nascituro, projeto de lei que aumentava puniçôes a condutas ligadas ao aborto e tentava garantir a vida de fetos concebidos em estupros, uma das hipóteses em que a legislação já permitia a interrupção da gravidez (Tadvald, 2010).

Aparentemente, tal campanha foi frutífera. Ao final do pleito de 2010, a FPE recebeu o acréscimo de trinta parlamentares, ou pouco mais de $50 \%$ se comparada com a legislatura iniciada em 2007. Dentre os deputados eleitos,

Debates do NER, Porto Alegre, ANo I6, N. 27, P. 259-288, JAN./Jun. 2015 
a FPE logrou a candidatura do deputado federal e pastor assembleiano Marco Feliciano (PSC-SP), que viria a ser presidente da Comissão de Direitos Humanos e Minorias (CDHM) da Câmara ${ }^{3}$, cargo que exerceu durante o ano de 2013, o que gerou controvérsias pelas diversas ações e declarações polêmicas de Feliciano, principalmente em relação a temas como direitos aos homossexuais e direito ao aborto. Dessa forma, Feliciano tornou-se, à época, uma espécie de porta-voz do dogmatismo e do conservadorismo nacional, voz essa projetada enfaticamente a partir do cargo que exerceu na Câmara.

Indicado por seu partido, o PSC, a eleição de Feliciano à presidência da CDHM em 2012 foi marcada por protestos de integrantes de movimentos pelos direitos humanos e sociais e pela atenção da mídia nacional. Isso porque, no ano anterior, o então deputado federal recebera certa visibilidade nacional ao publicar em sua conta no microblog Twitter manifestaçôes preconceituosas contra africanos e seus descendentes, bem como contra homossexuais: "sobre o continente africano repousa a maldição do paganismo, ocultismo, misérias, doenças oriundas de lá: ebola, Aids, fome... Etc" ou "a podridão dos sentimentos dos homoafetivos leva ao ódio, ao crime e à rejeição". Posteriormente, seguiu twittando posições semelhantes, como "africanos descendem de ancestral amaldiçoado por Noé. Isso é fato. O motivo da maldição é a polêmica. Não sejam irresponsáveis twitters rsss", entre outras manifestações de natureza correlata (Néri, 2013).

3 Conforme o sítio da CDHM, “[...] suas atribuições constitucionais e regimentais são receber, avaliar e investigar denúncias de violaçôes de direitos humanos; discutir e votar propostas legislativas relativas à sua área temática; fiscalizar e acompanhar a execução de programas governamentais do setor; colaborar com entidades não-governamentais; realizar pesquisas e estudos relativos à situação dos direitos humanos no Brasil e no mundo, inclusive para efeito de divulgação pública e fornecimento de subsídios para as demais Comissooes da Casa; além de cuidar dos assuntos referentes às minorias étnicas e sociais, especialmente aos índios e às comunidades indígenas, a preservação e proteção das culturas populares e étnicas do País". (CDHM. Disponível em: <http://www2. camara.leg.br/atividade-legislativa/comissoes/comissoes-permanentes/cdhm/conheca-acomissao/oquee.html>. Acesso em: 30 set. 2014).

Debates do NER, Porto Alegre, ano I6, N. 27, P. 259-288, JAn./Jun. 2015 
$\mathrm{Na}$ época, o líder do PSOL, deputado Ivan Valente (SP), afirmou que a comissão não teria condições políticas de funcionar caso Feliciano fosse eleito, pois conforme discurso proferido na Câmara, o deputado sentenciou que "[...] essa comissão trata de questôes sobre direitos inalienáveis. Luta contra o preconceito, contra o racismo. A comissão precisa ter alguém que represente esses valores. A manutenção do nome do deputado Feliciano é uma radicalização inaceitável”. O deputado Jean Wyllys, também do PSOL (RJ) e reeleito no pleito de 2014, figura política que tem se notabilizado pela defesa de pautas que colidem com a cosmologia da FPE, à época declarou ser, a respeito da candidatura de Feliciano,

Radicalmente contra, não voto nele, fiz a articulação com os deputados pra que a gente esvaziasse a comissão pra ele não ter maioria, pra não legitimar a eleição dele. E minha questão não é pessoal. É política. Não é pelo fato dele ser pastor. Se ele fosse um pastor identificado com a luta das minorias, eu não faria oposição. $\mathrm{O}$ problema não está no cristianismo, nem dele ser pastor. Mas no fato dele ser racista, homofóbico e contrário aos direitos das minorias. (Wyllys apud Passarinho; Costa, 2013).

Ao cabo, devido a acordo entre os líderes dos partidos da Câmara, a presidência dessa comissão foi entregue na ocasião ao PSC e, consequentemente, ao seu deputado indicado Marco Feliciano, eleito em março de 2013, na Câmara, sob protestos e a portas fechadas. O PT, sigla que presidiu o colegiado em 2012, abriu mão desta estrutura em troca da comissão de Relações Exteriores, o que deixou Feliciano na condição de candidato único. Durante a posse, Feliciano negou ser racista, ao declarar que:

O trabalho que nós vamos executar aqui vai mostrar ao povo brasileiro. Caso eu houvesse cometido esse crime de racismo, a primeira pessoa para quem eu teria que pedir perdão na vida seria a minha mãe [...]. Uma senhora de matriz negra, só não tem a sua matiz negra - só a pele dela não é negra -, mas o sangue é negro, os lábios são negros, o coração dela é, como eu também sou. (Feliciano apud Néri, 2013). 
Apesar de se tratar de uma das Comissões parlamentares de menor prestígio se levamos em consideração a distribuição - e disputa entre os partidos - pela presidência desses colegiados permanentes (21 ao total), sendo a CDHM uma das últimas comissões a receber a atenção partidária na Câmara, em sua presidência, o deputado pode colocar ou retirar de pauta projetos de lei relacionados a direitos humanos e à defesa de certas minorias, além de tornar tal comissão uma espécie de amplificador de posições peculiares, neste caso, de uma específica cosmologia ou ethos evangélico e conservador. Aí reside a sua maior importância no cenário político institucional do país, o que explica em parte a grande atenção da mídia e da sociedade recebidas ultimamente, algo inédito em se tratando desse colegiado.

Ao longo de seu mandato junto a CDHM, Feliciano fez valer o seu papel de porta-voz desse ethos conservador, atuando e se posicionando de forma crítica diante dos temas polêmicos já referidos (aborto, homoafetividade, legalização de drogas etc.), recebendo, dessa forma, uma visibilidade social considerável no período, inclusive no que dizia respeito aos processos judiciais que respondia à época (como por estelionato, já deferido pelo Supremo Tribunal Federal em favor do réu e de homofobia, ainda em curso). Sob campanha em 2014, Feliciano foi reeleito deputado federal no último pleito pelo PSC-SP com quase 400 mil votos. Atualmente, a CDHM é presidida pelo agricultor e deputado Assis do Couto, do PT paranaense. Pela sua presidência não estar ocupada por um político evangélico, a atenção social que repousava sob a CDHM atualmente arrefeceu de forma considerável.

A atuação de Feliciano junto à CDHM e da FPE em geral durante a última legislatura indicou uma forte preocupação com temas relacionados ao movimento LGBT (lésbicas, gays, bissexuais e transgêneros) e a manutenção da criminalização do aborto. Não por acaso, mais recentemente, a FPE também tem sido intitulada de Frente Parlamentar da Família e Apoio à Vida. Ainda, durante a presidência de Feliciano, em 2013, a CDHM conseguiu a aprovação do projeto que ficou conhecido como "cura gay", que permitiria a psicólogos promoverem tratamentos para "curar a homossexualidade". Nesse

Debates do NER, Porto Alegre, ano I6, N. 27, P. 259-288, JAn./Jun. 2015 
mesmo ano, o deputado assembleiano e ex-presidente da FPE, João Campos (PSDB-GO), afirmou que a bancada evangélica discutiria medidas contra a decisão do Conselho Nacional de Justiça de obrigar cartórios a celebrar casamentos entre cidadãos de mesmo sexo, medida à época polêmica, por considerar que o Poder Judiciário estaria sobrepujando desígnios do Poder Legislativo. Em ambos os casos, as medidas não frutificaram, assim como o pedido de revogação impetrado em agosto de 2013 pela FPE, tendo em vista a sanção da lei que tornava obrigatória políticas do Ministério da Saúde no atendimento a vítimas de violência sexual (como a oferta de pílula do dia seguinte e aborto após estupro). No caso da "cura gay", o projeto que prevê a derrubada de uma resolução do Conselho Federal de Psicologia (CFP) que proíbe aos profissionais da área prestar atendimento ou orientação a homossexuais que estejam descontentes com sua opção sexual e desejam mudar sua orientação trata-se, na verdade, de um retrocesso jurídico tendo em vista a resolução que vigora desde maio de 1990 da Organização Mundial de Saúde (OMS) que retirou a homossexualidade da lista internacional de doenças.

O pastor Eurico (PSB-PE), integrante da FPE reeleito em 2014 e autor do projeto da "cura gay", também se notabilizou enquanto parlamentar ao hostilizar publicamente a apresentadora Xuxa Meneghel ${ }^{4}$, em agosto de 2013, durante sessão da Comissão de Constituição e Justiça da Câmara (CCJ) sobre a Lei da Palmada (projeto de lei que proíbe a aplicação de castigos físicos a menores de idade), projeto que, enfim, só foi aprovado após alteração no texto final para atender à bancada evangélica.

4 Na ocasião, segundo noticiado, quando evangélicos cobravam do presidente em exercício, Luiz Couto (PT-PE), o encerramento da sessão, o deputado Pastor Eurico hostilizou a apresentadora e disse que sua presença era "um desrespeito às famílias do Brasil". "A conhecida Rainha dos Baixinhos, que no ano de 82 provocou a maior violência contra as crianças", disse, referindo-se ao filme Amor Estranho Amor, daquele ano, em que Xuxa aparece numa cena de sexo com um menor de 12 anos. No final, devido ao imbróglio, o pastor Eurico foi destituído da CCJ pelo então presidente e correligionário Beto Albuquerque (PSB-RS), mas o texto final foi alterado conforme o desejo da FPE.

Debates do NER, Porto Alegre, ano i6, N. 27, P. 259-288, JAn./Jun. 2015 
Este conjunto de ações promovidas pela FPE indica em boa medida as diretrizes vindouras da próxima legislatura e a atuação desta bancada junto às casas do Poder Legislativo nacional. A sua atividade na legislatura 2011-2014 colocou a bancada evangélica em outro patamar em termos de visibilidade e de reverberação dos seus posicionamentos, de forma que, nestes últimos anos, a sociedade nacional, em alguma medida, aprendeu a prestar mais atenção nas suas posições e a discuti-las, o que, malgrado análises mais imediatas ou tendenciosas, tende a fortalecer $o$ processo democrático.

\section{A LEGISLATURA VINDOURA (2015-2018)}

A retomada do crescimento parlamentar evangélico, portanto, foi creditada pelo campo pentecostal principalmente aos ataques deste segmento às iniciativas originárias da sociedade civil a favor da descriminalização do aborto e da criminalização da homofobia e do casamento civil entre pessoas do mesmo sexo. Todas essas questôes repercutem certo ethos conservador tipicamente cristão há muito enraizado na nação. Por isso é que a presença dos evangélicos na política chama tanto a atenção da sociedade nacional nos últimos tempos, oferecendo à nação uma chance especial de se defrontar com seu histórico limite social causado pelo conflito entre o ideal de pluralidade e a moral conservadora, por conseguinte, um conflito inerente à sua própria identidade. Talvez inédito em tais proporçôes, a atual ampliação das políticas de identidade e a decorrente visibilidade de outras identidades nacionais têm forçado o ethos conservador do país a se mostrar diante da nação, algo que ele pouco precisou fazer ao longo dos tempos devido ao seu forte enraizamento e subsequente naturalização.

Assim, nos últimos tempos, a partir, principalmente, da atuação de setores evangélicos, o ethos cristão conservador registrado em nossas estruturas mentais e do poder institucionalizado, mormente não revelou o seu crescimento, mas, antes, a sua exposição. Portanto, não é possível meramente considerarmos que, mediante a ascensão de certos grupos sociais, nossa

Debates do NER, Porto Alegre, ano I6, N. 27, P. 259-288, JAn./Jun. 2015 
sociedade tem se tornado mais conservadora, mas, na realidade, constatarmos que ela nunca deixou de sê-lo. A presença evangélica na política apenas revela uma atualização desse ethos, desse traço da nação.

A campanha eleitoral de 2014 indicou tais pressupostos. Contudo, o ethos conservador da nação não esteve restrito aos candidatos religiosos. Ele também esteve reverberado na campanha presidencial, especialmente na figura dos candidatos Pastor Everaldo (PSC) e Levy Fidelix (PRTB) 5 .

Pastor Everaldo, vice-presidente nacional de sua legenda, é ligado à Assembleia de Deus de Madureira, no Rio de Janeiro. Antes mesmo da campanha eleitoral, o candidato já fora considerado "inimigo público" por ativistas dos direitos LGBT, devido ao fato de ter sido um dos idealizadores da campanha "Homem + Mulher = Família”, promovida pelo PSC em 2012. Ele também recebeu críticas de defensores dos direitos dos homossexuais por afirmar que, se fosse eleito presidente da República, iria somar esforços à FPE ao propor um projeto de lei ao Congresso Nacional para reverter a decisão do Conselho Nacional de Justiça (CNJ) que passava a reconhecer o casamento entre pessoas do mesmo sexo em todo o território nacional. $\mathrm{O}$ pastor também recebeu críticas de setores ligados aos direitos das mulheres por ser contrário ao direito ao aborto. Durante a campanha presidencial de 2014, Everaldo também posicionou-se de forma contrária a propostas de "legalização das drogas" e se autointitulou um "defensor da família como está na Constituição", o que causou constrangimento aos simpatizantes e

5 Somado a tais personagens, é digno de nota a atuação do militar da reserva e deputado federal pelo Rio de Janeiro Jair Bolsonaro (PP), o qual, desde que assumiu o seu primeiro mandato, em 1991, faz coro a certas posiçōes da FPE no Congresso Nacional. O deputado ganhou notoriedade nacional após dar declaraçôes sobre questôes polêmicas como homofobia, preconceito racial, sexismo, cotas raciais, instauração da pena de morte, discriminação de povos indígenas, bem como defesa da tortura e do regime militar no Brasil, sendo classificado por alguns especialistas como representante da extrema-direita brasileira. Bolsonaro assumiu em 2015 o seu sexto mandato parlamentar, tendo sido o terceiro deputado federal mais votado do país em 2014, com mais de 464 mil votos.

Debates do NER, Porto Alegre, ANo I6, N. 27, P. 259-288, JAN./Jun. 2015 
militantes dessas bandeiras sociais. Tal constrangimento também foi promovido pelo "candidato secular" Levy Fidelix, quando este não se furtava em declarar posiçôes polêmicas diante das questôes sociais que atravessam essa discussão. Por exemplo, em um dos debates televisivos entre postulantes à Presidência, Fidelix respondeu a então candidata pelo PSOL, Luciana Genro, a respeito das políticas públicas para homoafetivos e integrantes do movimento LGBT relacionando homossexualidade a pedofilia:

Aparelho excretor não reproduz [...]. Como é que pode um pai de família, um avô ficar aqui escorado porque tem medo de perder voto? Prefiro não ter esses votos, mas ser um pai, um avô que tem vergonha na cara, que instrua seu filho, que instrua seu neto. Vamos acabar com essa historinha. Eu vi agora o santo padre, o papa, expurgar, fez muito bem, do Vaticano, um pedófilo. Está certo! Nós tratamos a vida toda com a religiosidade para que nossos filhos possam encontrar realmente um bom caminho familiar. [E na réplica a esta resposta arrematou] Então, gente, vamos ter coragem, nós somos maioria, vamos enfrentar essa minoria. Vamos enfrentá-los. Não tenha medo de dizer que sou pai, uma mãe, vovô, e o mais importante, é que esses que têm esses problemas realmente sejam atendidos no plano psicológico e afetivo, mas bem longe da gente, bem longe mesmo porque aqui não dá. (Fidelix apud $\mathrm{ZH}$ eleiçōes 2014, grifo nosso) ${ }^{6}$.

Ainda que não passassem de meros coadjuvantes no cenário eleitoral para o Executivo nacional, a exposição na mídia a que tiveram direito e acesso os candidatos Pastor Everaldo e Levy Fidelix foi bem aproveitada no sentido de reverberar, reforçar e atualizar o discurso conservador e aviltar o enfrentamento evangélico (mas, como visto, não somente religioso) perante aquelas questóes consideradas fundamentais em sua exegese política.

\footnotetext{
6 Após este debate, a hashtag \#LevyVocêÉNojento ocupava os Trending Topics do Twitter, quer dizer, quando um assunto (mediante uma hashtag) é mencionado com muita frequência em um curto período de tempo na plataforma do microblog.
}

Debates do NER, Porto Alegre, ano I6, N. 27, P. 259-288, JAn./Jun. 2015 
Retomando a campanha ao Legislativo federal, no que diz respeito aos partidos, em 2014, o PRB (Partido Republicano Brasileiro) constituiu-se na legenda par excellence da IURD. Lançou diversos candidatos da Universal à Câmara dos Deputados e também ao Senado, além de apoiar a candidata governista Dilma Rousseff, da coalizão petista durante o pleito. O PSC (Partido Social Cristão), do candidato Pastor Everaldo, conta entre filiados com membros das Assembleias de Deus e de outras igrejas evangélicas, como a do Evangelho Quadrangular, denominações das quais lançou diversos candidaturas no país. O PR (Partido da República), também coalizante na campanha de Dilma Rousseff, concentrou a candidatura ao Senado e à Câmara de membros das Assembleias de Deus e das igrejas Batista e Presbiteriana, especialmente das comunidades religiosas fluminenses. Estes são os três principais partidos políticos brasileiros que atualmente representam grande parte das candidaturas evangélicas pelo país, entretanto, a influência evangélica não se restringiu somente a eles, havendo representantes e candidatos em praticamente todas as demais legendas. Dentre outros aspectos, a composição da atual FPE, representada no quadro a seguir, revela este traço partidário multifacetado. 
Quadro 2 - Composição da FPE (2015-2018) ${ }^{7}$

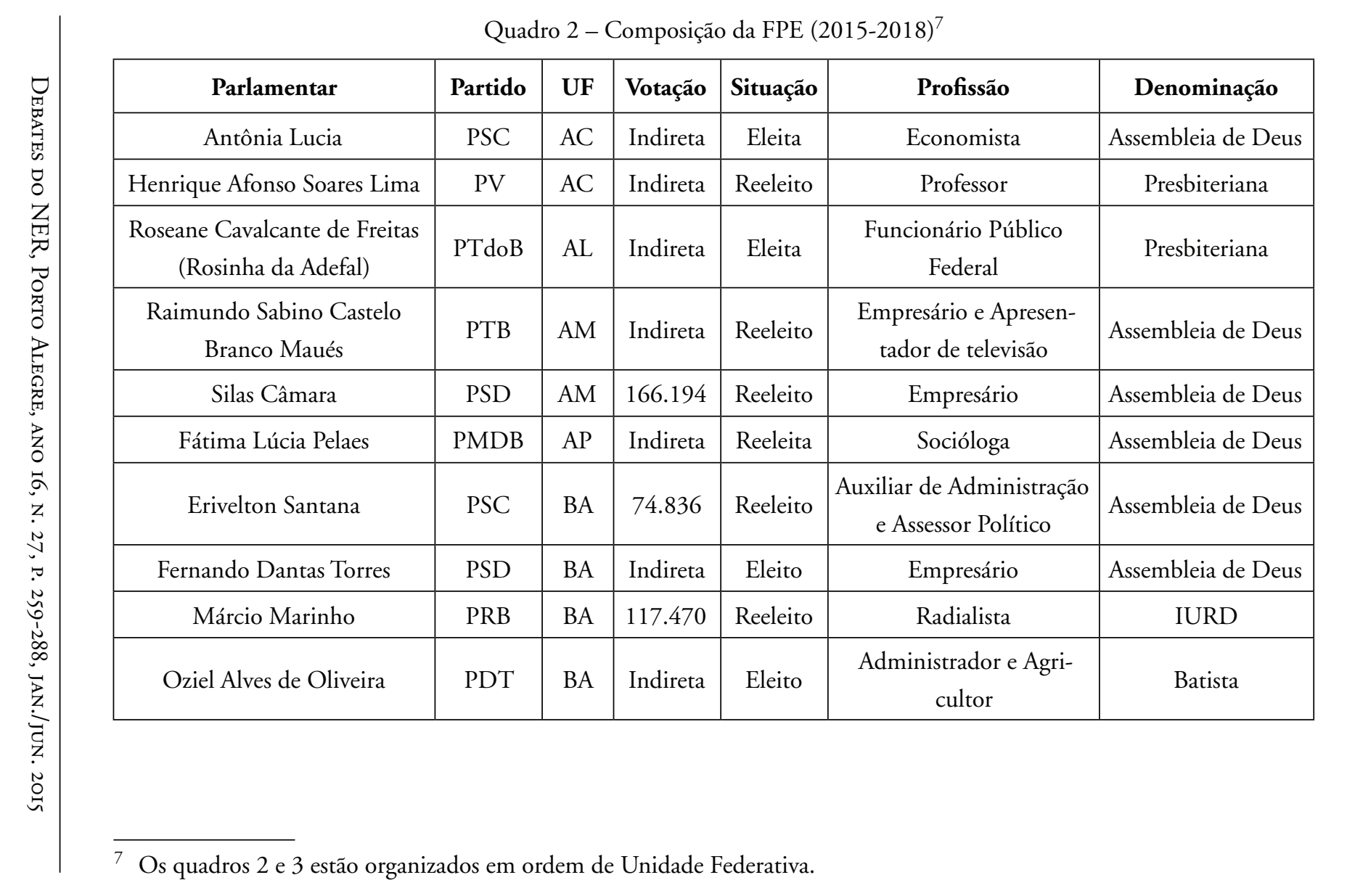




\begin{tabular}{|c|c|c|c|c|c|c|}
\hline Sérgio Brito & PSD & $\mathrm{BA}$ & 83.658 & Reeleito & $\begin{array}{c}\text { Empresário, Servidor } \\
\text { Público e Administrador } \\
\text { de Empresas }\end{array}$ & Batista \\
\hline Ronaldo Fonseca & PROS & DF & 84.583 & Reeleito & Advogado & Assembleia de Deus \\
\hline Carlos Humberto Mannato & SD & ES & 67.631 & Reeleito & Médico & Cristã Maranata \\
\hline Lauriete Rodrigues Pinto & PSC & ES & Indireta & Eleita & Empresária & Assembleia de Deus \\
\hline Sueli Vidigal & PDT & ES & 161.744 & Reeleita & Funcionário Público & Batista \\
\hline Íris Rezende & PMDB & $\mathrm{GO}$ & Indireta & Reeleito & Administrador Público & Cristã Evangélica \\
\hline João Campos & PSDB & $\mathrm{GO}$ & 107.344 & Reeleito & Delegado de Polícia & Assembleia de Deus \\
\hline Davi Alves Silva Júnior & PR & MA & Indireta & Reeleito & Empresário & Adventista \\
\hline $\begin{array}{l}\text { Lourival Mendes da Fonseca } \\
\text { Filho }\end{array}$ & PTdoB & MA & Indireta & Eleito & Delegado de Polícia & Batista \\
\hline José Vieira Lins & PROS & MA & Indireta & Reeleito & Empresário & Assembleia de Deus \\
\hline Lincoln Portela & PR & MG & 98.834 & Reeleito & Radialista e Comunicador & Batista Nacional \\
\hline Leonardo Quintão & PMDB & MG & 118.470 & Reeleito & Empresário & Presbiteriana \\
\hline George Hilton & PRB & MG & 146.792 & Reeleito & $\begin{array}{c}\text { Radialista, Apresentador } \\
\text { de Televisão, Teólogo e } \\
\text { Animador }\end{array}$ & IURD \\
\hline
\end{tabular}




\begin{tabular}{|c|c|c|c|c|c|c|}
\hline Rodrigo Moreira Ladeira Grilo & SD & MG & Indireta & Eleito & Advogado & $\begin{array}{c}\text { Internacional da } \\
\text { Graça de Deus }\end{array}$ \\
\hline Stefano Aguiar dos Santos & PSB & MG & Indireta & Eleito & Pastor evangélico & $\begin{array}{l}\text { Evangelho } \\
\text { Quadrangular }\end{array}$ \\
\hline Walter da Rocha Tosta & PSD & MG & Indireta & Eleito & Autônomo & Batista \\
\hline Weliton Prado & PT & MG & 186.098 & Reeleito & Bacharel em Filosofia & Assembleia de Deus \\
\hline José da Cruz Marinho & PSC & PA & Indireta & Reeleito & $\begin{array}{c}\text { Técnico em contabilidade } \\
\text { e Pedagogo }\end{array}$ & Assembleia de Deus \\
\hline Josué Bengtson & РTB & PA & 122.995 & Reeleito & Pastor Evangélico & $\begin{array}{c}\text { Evangelho } \\
\text { Quadrangular } \\
\end{array}$ \\
\hline $\begin{array}{c}\text { Major Fábio Rodrigues de } \\
\text { Oliveira }\end{array}$ & PROS & PB & Indireta & Reeleito & Policial Militar & Assembleia de Deus \\
\hline Anderson Ferreira & PR & PE & 150.565 & Reeleito & Empresário & Assembleia de Deus \\
\hline Pastor Eurico & PSB & PE & 233.762 & Reeleito & $\begin{array}{l}\text { Comerciário e Comuni- } \\
\text { cador de Rádio }\end{array}$ & Assembleia de Deus \\
\hline Zacarias Vilharba & PP & PE & Indireta & Eleito & $\begin{array}{l}\text { Radialista e Pastor Evan- } \\
\text { gélico }\end{array}$ & IURD \\
\hline André Zacharow & PMDB & PR & Indireta & Reeleito & $\begin{array}{c}\text { Advogado, Economista, } \\
\text { Professor }\end{array}$ & Batista \\
\hline
\end{tabular}




\begin{tabular}{|c|c|c|c|c|c|c|}
\hline Takayama & PSC & PR & 162.952 & Reeleito & $\begin{array}{c}\text { Empresário, Professor e } \\
\text { Ministro Evangélico }\end{array}$ & Assembleia de Deus \\
\hline Delegado Francischini & SD & PR & 159.569 & Reeleito & $\begin{array}{c}\text { Empresário e Delegado de } \\
\text { Polícia Federal }\end{array}$ & Assembleia de Deus \\
\hline Edmar Arruda & PSC & PR & 85.155 & Reeleito & Empresário e Economista & $\begin{array}{c}\text { Mundial do Poder } \\
\text { de Deus }\end{array}$ \\
\hline Adilson Soares & PR & RJ & Indireta & Reeleito & Advogado & $\begin{array}{l}\text { Internacional da } \\
\text { Graça de Deus }\end{array}$ \\
\hline $\begin{array}{c}\text { Andréia Almeida Zito dos } \\
\text { Santos }\end{array}$ & PSDB & RJ & Indireta & Reeleita & Advogada & Cristã Maranata \\
\hline Anthony Garotinho & PR & RJ & Indireta & Eleito & Radialista & Presbiteriana \\
\hline Arolde de Oliveira & PSD & RJ & 55.380 & Reeleito & $\begin{array}{l}\text { Empresário, Engenheiro, } \\
\text { Economista e Professor }\end{array}$ & Batista \\
\hline Áureo Lídio Moreira Ribeiro & SD & RJ & Indireta & Eleito & Empresário & Metodista \\
\hline Benedita da Silva & PT & $\mathrm{RJ}$ & Indireta & Eleita & $\begin{array}{l}\text { Assistente Social, Auxiliar } \\
\text { de Enfermagem, Profes- } \\
\text { sora, Servidor Público }\end{array}$ & Presbiteriana \\
\hline Eduardo Cunha & PMDB & RJ & 232.708 & Reeleito & Empresário e Economista & Sara Nossa Terra \\
\hline Filipe de Almeida Pereira & PSC & RJ & Indireta & Eleito & Empresário & Assembleia de Deus \\
\hline
\end{tabular}




\begin{tabular}{|c|c|c|c|c|c|c|}
\hline Francisco Floriano & PR & RJ & 47.157 & Reeleito & $\begin{array}{l}\text { Apresentador de Televisão, } \\
\text { Locutor, Publicitário, } \\
\text { Representante Comercial }\end{array}$ & $\begin{array}{c}\text { Mundial do Poder } \\
\text { de Deus }\end{array}$ \\
\hline Liliam Sá de Paula & PROS & RJ & Indireta & Eleita & $\begin{array}{c}\text { Apresentadora de Tele- } \\
\text { visão e Radialista }\end{array}$ & Assembleia de Deus \\
\hline Vitor Paulo Araújo dos Santos & PRB & RJ & Indireta & Eleito & Jornalista e Radialista & IURD \\
\hline Walney da Rocha Carvalho & PTB & RJ & Indireta & Eleito & Servidor Público Estadual & Metodista \\
\hline Washington Reis & PMDB & RJ & 103.190 & Reeleito & Empresário e Economista & Nova Vida \\
\hline Marcos Rogério & PDT & $\mathrm{RO}$ & 60.780 & Reeleito & $\begin{array}{c}\text { Jornalista e Bacharel em } \\
\text { Direito }\end{array}$ & Assembleia de Deus \\
\hline Nilton Capixaba & PTB & $\mathrm{RO}$ & 42.353 & Reeleito & Empresário & Assembleia de Deus \\
\hline Jhonatan de Jesus & PRB & $\mathrm{RR}$ & 20.677 & Reeleito & Empresário & IURD \\
\hline Onyx Lorenzoni & DEM & RS & 148.302 & Reeleito & $\begin{array}{c}\text { Empresário e Médico } \\
\text { Veterinário }\end{array}$ & Luterana \\
\hline Laércio Oliveira & SD & SE & 84.198 & Reeleito & $\begin{array}{l}\text { Empresário e Adminis- } \\
\text { trador de Empresas }\end{array}$ & Presbiteriana \\
\hline Marco Feliciano & PSC & SP & 398.087 & Reeleito & $\begin{array}{l}\text { Conferencista, Empre- } \\
\text { sário, Pastor Evangélico }\end{array}$ & Assembleia de Deus \\
\hline Jorge Tadeu Mudalen & DEM & SP & 178.771 & Reeleito & Engenheiro Civil & $\begin{array}{c}\text { Internacional da } \\
\text { Graça }\end{array}$ \\
\hline
\end{tabular}




\begin{tabular}{|c|c|c|c|c|c|c|}
\hline Bruna Furlan & PSDB & SP & 178.606 & Reeleita & Formada em Direito & $\begin{array}{c}\text { Congregação Cristã } \\
\text { no Brasil }\end{array}$ \\
\hline Jefferson Campos & PSD & SP & 161.790 & Reeleito & $\begin{array}{c}\text { Ministro do Evangelho, } \\
\text { Advogado, Tecnólogo, } \\
\text { Radialista, Bacharel em } \\
\text { Teologia } \\
\end{array}$ & $\begin{array}{c}\text { Evangelho } \\
\text { Quadrangular }\end{array}$ \\
\hline José Carlos Vaz de Lima & PSDB & SP & Indireta & Eleito & Agente Fiscal de Rendas & Presbiteriana \\
\hline Marcelo Aguiar & DEM & SP & Indireta & Eleito & Músico & Renascer \\
\hline Missionário José Olimpio & PP & SP & 154.597 & Reeleito & $\begin{array}{c}\text { Empresário e Comer- } \\
\text { ciante }\end{array}$ & $\begin{array}{c}\text { Mundial do Poder } \\
\text { de Deus }\end{array}$ \\
\hline Antônio Bulhōes & PRB & SP & 137.939 & Reeleito & $\begin{array}{c}\text { Empresário, Apresentador } \\
\text { de Televisão, Adminis- } \\
\text { trador, Teólogo e Bispo } \\
\text { Evangélico }\end{array}$ & IURD \\
\hline Edinho Araújo & PMDB & SP & 112.780 & Reeleito & Advogado, Professor & Presbiteriana \\
\hline Otoniel Carlos de Lima & PRB & SP & Indireta & Eleito & Militar da Reserva & IURD \\
\hline Paulo Freire & $\mathrm{PR}$ & SP & 111.300 & Reeleito & Ministro do Evangelho & Assembleia de Deus \\
\hline Roberto de Lucena & PV & SP & 67.191 & Reeleito & $\begin{array}{l}\text { Conferencista, Escritor, } \\
\text { Pastor Evangélico }\end{array}$ & O Brasil para Cristo \\
\hline
\end{tabular}

Fontes: DIAP (<www.diap.org.br>) e FPE (<http://www.fpebrasil.com.br/portal/index.php/os-deputados $>$ ). Acesso em: 7 jan. 2015. 
Completam o grupo de 67 parlamentares, formando, assim, a atual FPE, os senadores: Magno Malta (PR-ES, Igreja Batista), Walter Pinheiro (PT-BA, Igreja Batista) e Eduardo Lopes (PRB-RJ, IURD).

Trazendo à luz alguns recortes sobre o Quadro 2, observamos que as denominações campeãs nas urnas em 2014 permanecem as mesmas desde os pleitos passados: Assembleias de Deus (24 parlamentares), Presbiteriana e Batista (8 cada, além de dois senadores batistas), seguidas pela IURD (7 parlamentares e um senador). Excetuando-se as igrejas do Evangelho Quadrangular, a Internacional da Graça de Deus e a Mundial do Poder de Deus, que lograram cada uma três cadeiras no parlamento, as demais cadeiras da FPE dividem-se entre dez diferentes denominações com até dois parlamentares eleitos.

No que diz respeito à presença feminina, a FPE é composta por dez mulheres, algo em torno de $6,7 \%$ da bancada, percentual modesto, como tem sido a presença de mulheres no legislativo federal. Se na legislatura anterior as mulheres representavam 8,8\% na Câmara, o percentual geral subiu a 9,9\% nas eleições de $2014^{8}$.

Quanto aos Estados da Federação, o pleito de 2014 também não reservou grandes surpresas diante de seu histórico, dado que os maiores colégios eleitorais do país lograram a eleição do maior número de evangélicos para

\footnotetext{
8 Apenas a título de informação, no Senado, a eleição de 2014 só trocava um terço desta Casa. Assim, foram escolhidas cinco senadoras entre as 27 vagas disponíveis. Elas vão dividir espaço com outras seis que cumprem mandato até 2019. Com isso, serão 11 de um total de 81 senadores, ou 13,6\% da Casa. No que diz respeito aos pleitos para os Executivos estaduais que sempre ocorrem em conjunto com as eleições federais, em 2014 apenas uma mulher foi eleita Governadora de um Estado brasileiro: trata-se de Suely Campos (PP), eleita em Roraima, por ter ido ao segundo turno após substituir de última hora o marido, Neudo Campos, considerado "ficha-suja" e inelegível neste pleito. Em 2011, havia apenas duas mulheres no comando estadual: Roseana Sarney (PMDB), no Maranhão, e Rosalba Ciarlini (DEM), no Rio Grande do Norte. Nenhuma delas concorreu à reeleição. Historicamente, o número de governadoras nunca passou de $11 \%$. No pleito de 2014 , ainda foram eleitas sete vice-governadoras.
}

Debates do NER, Porto Alegre, ano I6, N. 27, P. 259-288, JAn./Jun. 2015 
a FPE, nesta ordem: Rio de Janeiro (13), São Paulo (12), Minas Gerais (7) e Bahia (5). Incluindo o Distrito Federal, das demais 27 Unidades Federativas do país, apenas sete não elegeram ao menos um parlamentar da FPE (CE, MS, MT, PI, RN, SC e TO). Alagoas e Paraíba, Estados que jamais haviam elegido deputados para Frente, debutaram em 2014, de maneira que, após este pleito, apenas Mato Grosso, Piauí e Rio Grande do Norte jamais elegeram diretamente deputados para FPE.

Do total de 67 deputados que compõem a bancada, 47 reelegeram-se. Desse total, cerca de 17 deputados partem para o terceiro mandato ou mais, ou seja, já foram reeleitos em pleitos anteriores. A presidente da frente, deputada Fátima Pelaes (PMDB-AP), conseguiu ser reeleita, ainda que de forma indireta ${ }^{9}$. Destes 67 atuais deputados evangélicos, nove não concorreram a nenhum cargo e cinco se candidataram a outros cargos, como governo estadual e Senado.

Por ocasião do término do pleito, em outubro de 2014, o Departamento Intersindical de Acompanhamento Parlamentar (DIAP) identificou outros 14 parlamentares eleitos que poderiam compor a FPE na legislatura 2015-2018, devido ao seu atrelamento a alguma denominação evangélica, por professarem

9 No vigente regime democrático brasileiro, os poderes legislativos são compostos a partir da eleição indireta, modelo em que se privilegia a distribuição das cadeiras parlamentares entre os partidos políticos e não conforme a votação direta de cada candidato(a). No caso do parlamento nacional, a distribuição procede conforme o cálculo do coeficiente eleitoral (resultado da população/número de vagas por Estado dividido pelo número de votos válidos). Assim chegaremos ao coeficiente partidário (este resultado do número de votos válidos de cada partido dividido pelo coeficiente eleitoral), ou seja, o número de cadeiras na Câmara que cada partido ou coligação receberá. Neste modelo, permite-se que um(a) candidato(a) "campeão de votos" consiga eleger consigo outros correligionários em detrimento de adversários mais bem votados. O término deste modelo tem sido proposto pela reforma política brasileira, mas encontra muita resistência na Câmara por parte de alguns partidos que se beneficiam deste modelo a cada eleição, conseguindo capitalizar mais cadeiras, como é o caso de algumas legendas atinentes à FPE.

Debates do NER, Porto Alegre, ANo I6, N. 27, P. 259-288, JAN./Jun. 2015 
a fé segundo alguma doutrina desta natureza ou por ocuparem cargos nas estruturas de instituiçōes religiosas - como pastores, missionários, bispos e sacerdotes, ou ainda por se tratarem de artistas da cena gospel. Entretanto, ainda que eleitos, até janeiro de 2015, tais parlamentares não assumiram o seu mandato na Câmara ou não aderiram publicamente à FPE, conforme a lista oficial de membros informada pelo sítio virtual da Frente, que serviu de base para a composição do quadro anterior (2). Conforme segue, os parlamentares do quadro a seguir que assumiram seus mandatos poderão ingressar na FPE, aumentando o número de 67 parlamentares reconhecido até o presente.

Debates do NER, Porto Alegre, ano I6, N. 27, P. 259-288, JAn./Jun. 2015 
Quadro 3 - Parlamentares considerados evangélicos eleitos em 2014 que não assumiram mandato ou que não aderiram à FPE até janeiro de 2015

\begin{tabular}{|c|c|c|c|c|c|c|}
\hline Parlamentar & Partido & UF & Votação & Situação & Profissão & Denominação \\
\hline Irmão Lázaro & PSC & BA & 161.438 & Novo & Músico & Batista \\
\hline Ronaldo Martins & PRB & CE & 117.930 & Novo & $\begin{array}{c}\text { Radialista, Músico, } \\
\text { Compositor e Cantor }\end{array}$ & IURD \\
\hline Fábio Sousa & PSDB & GO & 82.204 & Novo & Bispo e Escritor & Fonte da Vida \\
\hline Julia Marinho & PSC & PA & 86.949 & Nova & Pedagoga & Assembleia de Deus \\
\hline Rejane Dias & PT & PI & 134.157 & Nova & Administradora & Catedral do Reino \\
\hline Christiane Yared & PTN & PR & 200.144 & Nova & Empresária e Pastora \\
\hline Clarissa Garotinho & PR & RJ & 335.061 & Nova & Jornalista & Metodista \\
\hline Sóstenes Cavalcante & PSD & RJ & 104.697 & Novo & Sacerdote & Assembleia de Deus \\
\hline Marcos Soares & PR & RJ & 44.440 & Novo & $\begin{array}{c}\text { Advogado, Especialista em } \\
\text { Teologia Prática }\end{array}$ & $\begin{array}{c}\text { Evangelho } \\
\text { Quadrangular }\end{array}$ \\
\hline
\end{tabular}




\begin{tabular}{|c|c|c|c|c|c|c|}
\hline Antônio Jácome & PMN & $\mathrm{RN}$ & 71.555 & Novo & Médico e Pastor & Assembleia de Deus \\
\hline Carlos Gomes & PRB & RS & 92.323 & Novo & Pastor Evangélico & IURD \\
\hline Ronaldo Nogueira & PTB & RS & 77.017 & Novo & $\begin{array}{c}\text { Administrador de } \\
\text { Empresas }\end{array}$ & Assembleia de Deus \\
\hline Pastor Jony & PRB & SE & 53.455 & Novo & Pastor Evangélico & IURD \\
\hline Pastor Gilberto Nascimento & PSC & SP & 120.044 & Novo & $\begin{array}{c}\text { Advogado, Delegado } \\
\text { de Polícia e formado } \\
\text { em Teologia }\end{array}$ & Assembleia de Deus \\
\hline
\end{tabular}

Fonte: DIAP (www.diap.org.br). Acesso em: 7 jan. 2015. 
Este levantamento indica um aspecto importante: o de que um parlamentar evangélico não necessariamente compõe a FPE. Dessa forma, considerei na análise os dados reconhecidos no Quadro 2, que tem por base o sítio da FPE consultado em janeiro de 2015, quando este já havia indexado como membros os parlamentares suplentes que assumiram cadeiras na Câmara. Dos 67 parlamentares considerados, é possível que este número ascenda a até 81 parlamentares caso não exista fatores de impedimento legal ou pessoal (acúmulo de cargos públicos, constar na ficha-suja, desistência do mandato, falecimento etc.).

Uma leitura rápida do Quadro 3 mostra-nos que, dos quatorze parlamentares indexados, cinco pertencem às Assembléias de Deus, três à IURD e dois são Batistas, seguidos por parlamentares ligados a outras quatro denominações. Quatro são mulheres, todos foram eleitos para cumprir o primeiro mandato na Câmara e são pertencentes a onze diferentes Estados da Federação, com destaque para o Rio de Janeiro (3).

\section{CONSIDERAÇÕES FINAIS:}

\section{O CONSERVADORISMO REINVENTADO}

Se levarmos em consideração o percentual de evangélicos apresentado pelo Censo de 2010 (cerca de 22\% da população) e os deputados eleitos na legislatura seguinte (algo em torno de 15\%), veremos que o percentual de parlamentares cumpre razoavelmente com a lógica da democracia representativa. Assim, os evangélicos estão representados na Câmara conforme o seu percentual da população brasileira. Isto quer dizer que, em termos político -religiosos, o campo evangélico encontra-se à frente de outros segmentos no que diz respeito à corrida eleitoral, mas não necessariamente ele possui uma capacidade superior a de outros setores sociais na angariação de votos. Tampouco o seu sucesso eleitoral representa o aumento do ethos conservador cristão que atravessa a experiência social e moral brasileira, mas antes a sua maior exposição. 
No caso do catolicismo, que tem diminuído no Brasil em face do crescimento evangélico, este, de forma ou de outra, sempre esteve representado nas esferas institucionalizadas do poder nacional. Ocorre é que certo ethos evangélico - moldado por uma postura mais agressiva e de posicionamento público mais transparente e imanente baseado no dogmatismo cristão, o qual incide sobre a esfera dos costumes e da moralidade nacional - é reverberado com mais profundidade do que o discurso católico. A rigor, a maioria dos evangélicos e católicos em pouco distanciam-se quando postos à frente de questôes como o aborto, direitos sexuais ou a legalização de algumas substâncias psicoativas. A diferença é que deputados que professam ou que se guiam a partir da doutrina católica desde o nascimento da República jamais tiveram as suas posições políticas e morais avaliadas pela nação a partir do critério religioso, o que não acontece com os evangélicos atualmente. Assim, malgrado o declínio católico, o ethos cristão conservador da nação consegue se reinventar e se atualizar a partir da atuação evangélica no cenário político brasileiro.

Talvez isso explique porque, em certa medida, a sociedade nacional não observa alguns aspectos peculiares da atividade evangélica no parlamento nacional: primeiro, de que seus integrantes têm pouco em comum além do segmento religioso e de algumas pautas particulares, por pertencerem a partidos, ideologias e denominações diferentes, o que os enfraquece enquanto grupo de pressão fora das questōes que envolvam suas crenças, de modo que acabam limitando a sua atividade parlamentar à defesa de seus interesses ao invés da proposição de grandes projetos; segundo, que suas açóes geram visibilidade e críticas mais ferrenhas da sociedade devido, possivelmente, ao seu comportamento menos discreto ou por tratarem de valores morais e da esfera dos costumes; contudo, se a sociedade nacional prestasse mais atenção e se ocupasse a contento de outros tantos projetos de lei e discussões que são tramitados cotidianamente no parlamento brasileiro, poderíamos estar permanentemente a beira de revoltas populares; e, por fim, o terceiro aspecto consiste no fato de que a bancada evangélica conquistaria muito

Debates do NER, Porto Alegre, ano I6, N. 27, P. 259-288, JAn./Jun. 2015 
pouco caso não contasse com o apoio de outros parlamentares e de outras bancadas, personagens tão importantes quanto os colegas evangélicos, mas que invariavelmente passam desapercebidos nas questôes as quais se coadunam e nas quais a FPE toma a frente nos debates nacionais. A propósito, vale mencionar que o parlamento nacional para 2015-2018 tem sido considerado por especialistas como o de perfil mais conservador das últimas legislaturas, o que causou surpresa em face das manifestaçôes populares que marcaram o Brasil em junho de 2013 e que indicavam a ascensão ao poder de grupos mais liberais (Moreira, 2014; Rodrigues, 2014).

Em realidade, certos repositórios morais não contribuem para a promoção de políticas de igualdade típicos de uma ordem democrática que se fundamenta a partir de uma aspiração social de natureza pluralista. Este choque de perspectivas gera tensão e conflito no seio da nação e na construção de identidades, sejam elas políticas, religiosas, morais etc. Assim, um importante cenário para visualizarmos atualmente a tensão entre identidades nacionais contrastantes, cada qual representante de um ethos mais liberal ou mais conservador da nação (e ainda o que exista entre ambos), tem sido o campo político brasileiro desde a ascensão e proliferação de políticos evangélicos.

Da mesma forma, no campo cultural, naquilo que diz respeito à constituição das identidades religiosas no país, os evangélicos têm, ao seu modo, fortalecido e mantido o lugar proeminente do cristianismo herdado do catolicismo oficial que historicamente soube se enraizar nas esferas de poder, na cultura popular e em instâncias tão profundas do imaginário da nação. Portanto, no que diz respeito ao parlamento que se anuncia a partir de 2015 e a certos avanços sociais na esfera das leis, é mais previsível e indicado que certos setores da sociedade brasileira sigam contando com algumas arbitrariedades de nosso Poder Judiciário. 


\section{REFERENNCIAS}

CORTEN, André. Pentecôtisme et politique en Amérique Latine. Problèmes d'Amérique latine, Paris, n. 24, p. 17-32, 1996.

FONSECA, Alexandre Brasil. A maior Bancada Evangélica. Tempo e Presença, Rio de Janeiro, n. 302, p. 20-23, 1998.

FRESTON, Paul. Breve histórico do pentecostalismo brasileiro. In: ANTONIAZZI, Alberto et al. Nem anjos nem demônios: interpretaçôes sociológicas do pentecostalismo. Petrópolis: Vozes, 1994. p. 67-159.

The transnationalization of Brazilian Pentecostalism: the Universal Church of the Kingdom of God. In: CORTEN, André; MARSHALLFRATANI, Ruth (Org.). Between Babel and Pentecostalism: Transnational Pentecostalism in Africa and Latin America. Bloomington: Indiana University Press, 2001. p. 196-213.

MARIANO, Ricardo. Sociologia do crescimento pentecostal no Brasil: um balanço. Perspectiva Teológica, Belo Horizonte, v. 43, p. 11-36, 2011.

MOREIRA, Carlos André. Uma guinada à direita: o Brasil saiu das eleições com um parlamento mais conservador, o que vai ter repercussóes cruciais em questôes importantes para o país. Zero Hora, Porto Alegre, 12 out. 2014. Caderno PrOA, p. 4-5.

NÉRI, Felipe. Marco Feliciano é eleito presidente da Comissão de Direitos Humanos. Portal G1 de Notícias. Disponível em: <http://g1.globo.com/ politica/noticia/2013/03/marco-feliciano-e-eleito-presidente-da-comissao-dedireitos-humanos.html>. Acesso em: 30 set. 2013.

PASSARINHO, Natália; COSTA, Fabiano. Após protestos, eleição da Comissão de Direitos Humanos é cancelada. Portal G1 de Notícias. Disponível em: <http://g1.globo.com/politica/noticia/2013/03/apos-protestos -eleicao-da-comissao-de-direitos-humanos-e-cancelada.html>. Acesso em: 30 set. 2013.

Debates do NER, Porto Alegre, ano I6, N. 27, P. 259-288, JAn./Jun. 2015 
RODRIGUES, Lúcia. Ascensão teocrática: bancada religiosa, com destaque a evangélicos, vai atuar para impedir avanços nas liberdades individuais. Caros Amigos Especial: o poder das religiōes, Porto Alegre, Ano 18, n. 71, p. 20-22, nov. 2014.

TADVALD, Marcelo. Demonização da política ou a política demonizada? Os evangélicos e as eleições federais de 2006. Debates do NER, Porto Alegre, ano 7, n. 10, p. 79-88, 2006.

Eleitos de Deus e pelo povo: os evangélicos e as eleições federais de 2010. Debates do NER, Porto Alegre, ano 11, n. 18, p. 83-109, 2010.

- Adaptaçôes da fé: análise antropológica da transnacionalização da Igreja Universal entre Brasil e Argentina. 2013. 328 p. Tese (Doutorado em Antropologia Social) - Programa de Pós-Graduação em Antropologia Social, Universidade Federal do Rio Grande do Sul, Porto Alegre, 2013.

TREVISAN, Janine. A frente parlamentar evangélica: força política no estado laico brasileiro. Numen: revista de estudos e pesquisa em religião, Juiz de Fora, v. 16, n. 1, p. 581-609, 2013.

ZH ELEIÇÕES 2014. Levy Fidelix causa polêmica com declaraçôes sobre gays em debate. Disponível em: <http://zh.clicrbs.com.br/rs/noticias/eleicoes-2014/ noticia/2014/09/levy-fidelix-causa-polemica-com-declaracoes-sobre-gays-emdebate-4609164.html>. Acesso em: 2 out. 2014.

Recebido em: 05/01/2015

Aprovado em: 25/02/2015 